\section{Solar Physicists in Oxford}

The Solar Physics Section of the European Physical Society held its Triennial meeting in Oxford on 13-15 April 1981 the third such meeting organised by the Section, following the first in Florence in 1975 and the second in Toulouse in 1978. These meetings have attracted 150-200 solar physicists from most countries in Europe and testify to the strength and growing importance of solar physics within astronomy.

The theme of the Oxford meeting was solar activity, starting from the underlying causes in the interaction between the subphotospheric convection zone and magnetic fields, and continuing to solar flares, the highest energy manifestation of the active sun.

Reviews of recent work on the magnetic cycle and development of active regions demonstrated how the fundamental problems associated with solar and stellar activity will have to be resolved through observations at high spatial resolution and these are possible only for the solar atmosphere.

Since the advent of rocket and satelliteborne telescopes which can obtain images of the Sun in the extreme ultra violet and $\mathrm{X}$-ray regions, it has been realised that active regions are composed of sets of loops, whose structure is controlled by the local magnetic field and gas pressure. Much of the current work in this area is concerned with the thermal and MHD stability of these loops and with the constraints that the observed temperature and density structures can place on the processes heating the plasma.

Several reviews were given of recent results from the Solar Maximum Mission Satellite. This satellite has allowed for the first time the simultaneous study of active regions and flares over a broad spectral range, and thus over a range of heights and temperatures in the atmosphere. Whilst spectroscopic methods are revealing the temperature and density conditions during flares, imaging instruments are being used to show where and when flares occur in relation to the long term development of particular active regions.

The ability to resolve spatial structures in the solar atmosphere, taken together with the application of refined spectroscopic methods that are possible with the high proton fluxes, allow the Sun to be used as the basic laboratory for testing physics which is relevant to both other late-type stars and cosmic sources of EUV and X-ray emission.

Immediately prior to the main meeting, the Solar Physics Section organized a Workshop on "Near Future Plans for Solar Research". Delegates from 17 countries from all parts of Europe presented accounts of current research and their plans for the rest of the 1980 's. A remarkable consensus emerged concerning important priorities for future study: e.g. measurements of velocity and magnetic fields related to the development of emerging magnetic flux, and studies of small magnetic elements in the convective supergranulation structure. The meeting achieved its main aim of providing an informal forum for the exchange of ideas and the discussion of possible collaborations in theoretical work and in both ground-based and space-borne projects.

Of the ground-based programmes, the most ambitious concerns the development of a large high resolution European Solar Telescope situated in the Canary Islands. This project can be seen as a logical extension of the previous site-testing activities of the Joint Organization for a Solar Observatory.

Several countries will continue to participate in the USSR's Interkosmos and Prognoz series of rockets and satellites, with particular interest in $\mathrm{X}$-ray imaging and spectroscopy. The community within the European Space Agency is awaiting the outcome of representations to NASA concerning the US part of the two-spacecraft International Solar Polar Mission. The US spacecraft which includes experiments to study the corona near the Sun is threatened by recent budget cuts.

The strength of theoretical solar physics in Europe and its close involvement in analysis of new data are particularly encouraging because they make for a good return from participation in a variety of guest investigator programmes as opportunities arise.

There is keen European interest in two potential solar payloads for the Shuttle Spacelab: in the Solar Optical Telescope, at present under study within NASA, and in the complementary Grazing Incidence Solar Telescope, currently a potential ESA project. The future of these missions depends on the success of the Shuttle and it was with relief that participants watched its safe return on 14 April, after which they could continue their dinner and polish up their proposals for future experiments.

\section{Jordan}

\section{W. Roxburgh}

\section{Divisions}

As a result of the recent elections, the new Board of the Plasma Physics Division is comprised as follows:

R. Behrisch, MPI, Garching

H. de Kluiver, FOM, Nieuwegein

A. Gibson, JET, Abingdon

G. Grieger, MPI, Garching

J. Jacquinot, CEN-FAR, Fontenay-aux-Roses

R.V. Sagdeev, Moscow

M. Samain, CEN-FAR, Fontenay-aux-Roses

D.C. Schram, Univ. of Techn., Eindhoven

D. Sweetman, UKAEA, Culham

F. Troyon, EPFL, Lausanne

R. Wienecke, Plasma Res. Inst., Stuttgart

H. Wilhelmsson, Chalmers Univ., Göteborg

After the Lisbon meeting, the Board of the High Energy and Particle Physics Division elected as Chairman and Secretary respectively:

J.M. Charap, Queen Mary Coll., London

G. Wolf, DESY, Hamburg

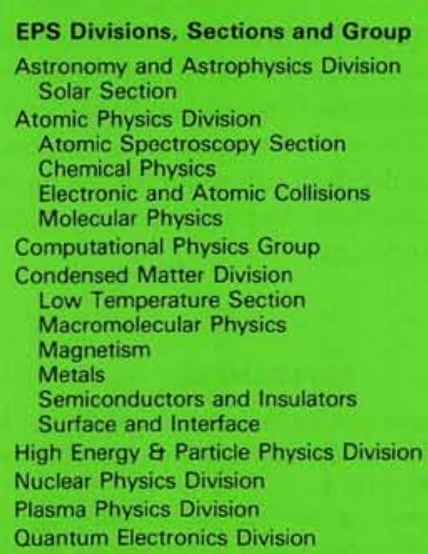

Europhysics News is the official journal of the European Physical Society that comprises 28 National Societies, Academies and Groups, over 3000 Individual Ordinary Members and 30 Associate Members. Governing bodies Members and 30 Associate Members. Governing bodies Executive Committee responsible for detailed policy. EPS promotes the collaboration of physicists throughout Europe and encourages all aspects of international exchange in physics. EPS awards scholarships for research and studies and makes arrangements for teaching abroad. EPS publishes, in addition to Europhysics News, Europhysics Conference Abstracts, the Proce6 dings of its General Conferences and (with the I.O.P.) the European Journal of Physics. Individual Ordinary Members receive Europhysics News (subscription for non-members: $75 \mathrm{Sw} . \mathrm{Fr}$./a), substantial rebates on publications and pay reduced fees at conferences Application for membership is made through the permanent Secretariat in Geneva. Annual subscription for members of a National Society is $32 \mathrm{Sw}$. Fr.
Editor: E.N. Shaw

Meetings Compilation: W.S. Newman

Editorial Board:

K. Appert, A. Baratoff, G.J. Béné,

G.R. Macleod, A. Maeder, J. Muller

Editorial and Advertising Office at the EPS Secretariat.

Address: EUROPEAN PHYSICAL SOCIETY P.O. Box 69 , CH-1213 Petit-Lancy 2 Switzerland

Telephone: Geneva (22) 931130

Telex: $23 \mathbf{4 5 5}$ alarm ch

Cables: europhys genève

Printed by: Pfirter frères SA CH-1213 Petit-Lancy/Switzerland 